\title{
The Impact of Material Selection on Durability of Exhaust Valve Faces of a Ship Engine - A Case Study
}

\author{
Hanna Smoleńska', Włodzimierz Kończewicz², Sylwia Bazychowska ${ }^{2 *}$ \\ 1 Gdansk University of Technology, Department of Materials Science and Engineering, Narutowicza 11/13, \\ 80-233 Gdansk, Poland \\ 2 Gdynia Maritime University, Department of Mechanical Engineering, Morska 83 81-225 Gdynia, Poland \\ * Corresponding author's e-mail: s.bazychowska@wm.umg.edu.pl
}

\begin{abstract}
Two alloys were used in order to extend the service life of marine engine exhaust valve head. Layers of cobalt base alloys were made of the powders with chemical composition as follow: the layer marked L12; C-1.55\%; Si-1.21\%; Cr-29.7\%; W-9\%; Ni-2\%; Mo<0.01\%; Fe-1.7\%; Co-54.83\% and the layer marked N; C-1.45\%; Co-38.9\%; Cr24.13\%; Ni-10.43\%; W-8.75\%; Fe-7.64\%; Mo-7.56\%; Si-2.59\%. Base metal was valve steel after heat treatment. It was consisted of: C-0,374\%; Cr-9,34\%; Mn-0.402\%; Ni-0.344\%; Si-2.46\%; Mo-0.822\%; P-0.0162\%; S- $0.001 \%$. Layers on the valve faces were produced by laser cladding using the HPDL ROFIN DL020 laser. Grinding treatment is a very popular form of regeneration of seat and valve plug adhesions. Properly performed grinding operation ensures dimensional and shape accuracy of the surface from 7 to 5 accuracy class and surface roughness Ra not less than $0.16 \mu \mathrm{m}$, depending on the object and method of grinding. The $75 \mathrm{H}$ and $150 \mathrm{~S}$ types are a significantly simplified form of valve plug face grinders. Finishing treatment was carried out with a Chris-Marine $\mathrm{AB} 75 \mathrm{H}$ sander on a sanding stand equipped with a compressed air system - the stand was designed by the author. The sander has been set up to the surface of the valve stem so that the grinding angle of the valve faces is $30^{\circ}+10^{\circ}$. A flat grinding wheel T1CRA54-K was used for machining. The plunge feed was $0.01 \mathrm{~mm} / \mathrm{rev}$. The thickness of the welded layer after grinding was $1.2 \mathrm{~mm}$. Both valves were installed in the ship's engine and were used in real life. After 2000 hours of operation, the valve marked $\mathrm{N}$ was damaged. The valve marked L12 showed no damage and was in operation for the next 1000 hours.
\end{abstract}

Keywords: cobalt alloy, laser cladding, exhaust valve.

\section{INTRODUCTION}

Proper selection of materials for specific applications is a key issue ensuring the correct and long-term use of machine parts and installations. Special difficulties arise when a structural element is affected by complex conditions, such as:

- variable mechanical loads, especially fatigue,

- friction wear processes,

- high temperatures,

- aggressive work environment.

Such a set of material requirements is found in the cases of marine engines exhaust valves operating under a heavy load.

The operating factors having the greatest impact on the technical condition of the exhaust valves of the marine engines are primarily $[10,11,12]$ :

- combustion process which (due to incorrect injection timing or poor fuel quality) accelerates the wear of valve components exposed to exhaust gases;

- valve clearance - too low clearance value can lead, in a short time, to burning the valve seat, while too high clearance leads, in turn, to a long-term mechanical punching of the seat;

- the cooling quality of the valve seat, its deterioration shortens the service life of both the seat and the head of exhaust valve.

It has been confirmed that the steel valves intended for such products do not meet the requirements. Therefore, the face area subjected to the 
most intense loads of various types -is covered with various materials, especially cobalt and nickel based alloys [1, 2, 3, 5, 8]. These materials are required to have, above all, high corrosion resistance in the exhaust environment and resistance to wear (high hardness under operating conditions) $[4,6,7]$. Despite the usage of such solutions, various types of damage listed below may occur:

- loss of tightness caused by corrosion pits resulting from erosive exhaust fumes (Fig. 1b),

- over burning of the valve head edges caused by the flow of extremely hot gases through the leaks (Fig. 1a),

- cracks, scratches and splinters caused by fatigue of the face layer (Fig. 1c).

Typical materials used for hard-surfaced surfaces are nickel-based alloys or Stellite, Deloro, Triballoy type cobalt.

Cobalt base alloys, because of their good combination of high rupture strength and excellent hot corrosion resistance at high temperatures, have been widely used. Cladded layer made of cobalt base alloys consist of a continuous fcc matrix and a variety of carbides, mainly primary ones, such as $\mathrm{M}_{23} \mathrm{C}_{6}, \mathrm{M}_{7} \mathrm{C}_{3}$ and $\mathrm{M}_{6} \mathrm{C}$, which form as the alloys solidify. Subsequent aging or service at elevated temperatures causes a large amount of secondary carbide precipitation, commonly $\mathrm{M}_{23} \mathrm{C}_{6}$. The fine secondary carbide precipitates are more effective in strengthening the

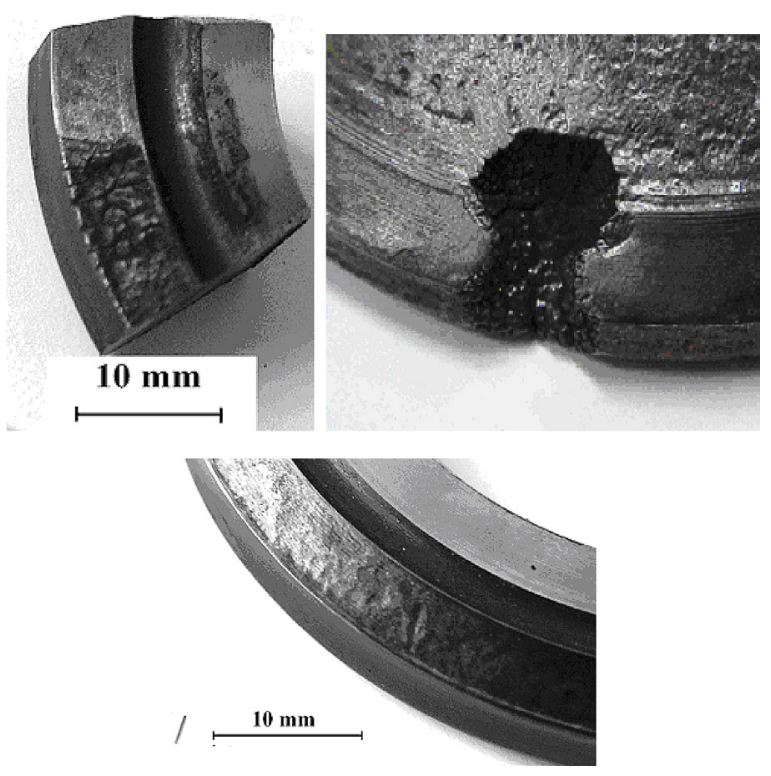

Fig. 1. Examples of damaged exhaust valve of the marine engine: (a) corrosion of the face - "pavement"; (b) destruction of the face and substrate due to valve leaks - irreparable; (c) face wear - repairable alloy matrix $[15,26]$. In these alloys, chromium forms carbides, which strengthen the cobalt matrix. Other elements are added to improve various properties - tungsten and molybdenum have large atomic radii, which distort the lattice providing strength [13].

\section{EXPERIMENTAL}

Usually tests were carried out using simulation of engine chamber [11]. This paper presents the behaviour of the clad layers on the faces of the exhaust valve made of two alloys operating in real conditions, during normal work on a ship. In both cases, laser welding was performed using the HPDL ROFIN DL020 laser. The process parameters are specified in Table 1.

Laser welding of the valve face was carried out with a high-power HPDL diode laser from ROFIN SINAR DL 020 with a maximum beam power of $2,3 \mathrm{~kW}$. The laser has a head equipped with two diodes, a laser beam power control system and a packet cooling system with diodes. The object of the study was two materials marked as L12 and N. Both of them were cobalt base alloys. These materials are characterized by high resistance to abrasion and corrosive conditions $[3,11,17,28]$. The alloy marked as L12 was stellite 12 type and it was made from the powder with chemical composition was (in \% by mass): C-1.55\%; Si-1.21\%; Cr-29.7\%; W-9.0\%; $\mathrm{Ni}-2.0 \%$; $\mathrm{Mo}<0.01 \%$; Fe- $1.7 \%$; $\mathrm{Co}-54.83 \%$. The second one marked in this article as $\mathrm{N}$ was similar to stellite 21 however it was enriched with nickel and tungsten. Enriching in tungsten was made in order to improve wear resistance [18]. Nickel alloy are widely used in marine technology of valves and this alloys may be cheaper than cobalt and might be better option. Ship engine valves welded with nickel-alloyed materials are particularly exposed to high-temperature corrosion. In this case it is absolutely necessary to use fuel with minimum Sulphur and vanadium content in the operation of engines. In plasma welding nickel alloys were used. But the fuel had to be low-Sulphur with a small amount of vanadium, because nickel lead to high-temperature corrosion. Alloys Nimonic 105, Nimonic 80A and MARAGIN C250, C300 and C350 in their composition as the main component contains nickel, cobalt and molybdenum. They are used for ship casings, hulls, rotor blades and steam turbines, 
Table 1. Technological conditions of laser powder welding with HPDL ROFIN DL020 laser.

\begin{tabular}{|c|c|c|c|c|c|}
\hline Layer parameters & $\begin{array}{c}\text { laser power } \\
{[\mathrm{kW}]}\end{array}$ & $\begin{array}{c}\text { Welding speed } \\
{[\mathrm{m} / \mathrm{min}]}\end{array}$ & $\begin{array}{c}\text { The intensity of } \\
\text { powder feed }[\mathrm{g} / \mathrm{min}]\end{array}$ & $\begin{array}{c}\text { Bead thickness } \\
{[\mathrm{mm}]}\end{array}$ & $\begin{array}{c}\text { Bead wideness } \\
{[\mathrm{mm}]}\end{array}$ \\
\hline 1 layer -2 beads & $1.0-1.2$ & 0.20 & 5.0 & $1.0-1.2$ & $5.5-6.0$ \\
\hline 2 and 3 layer -2 beads & $1.1-1.2$ & 0.20 & 5.0 & $1.3-1.5$ & $6.0-6.5$ \\
\hline
\end{tabular}

Table 2. Performance characteristics of L22 engine during the test period.

\begin{tabular}{|c|c|c|c|c|c|}
\hline \multicolumn{2}{|c|}{ Working Time } & \multicolumn{2}{|c|}{ Average load } & \multirow{2}{*}{ RPM } & \multirow{2}{*}{$\begin{array}{l}\text { The temperature in the cylinder } \\
\qquad\left[{ }^{\circ} \mathrm{C}\right]\end{array}$} \\
\hline Year & Hours & {$[\%]$} & {$[\mathrm{kW}]$} & & \\
\hline 2006 & $160 \mathrm{~h} 30 \mathrm{~min}$ & & & & \\
\hline 02-06.2006 & $44 \mathrm{~h} 15 \min$ & 60 & & 225 & 330 \\
\hline 06-07.2006 & 19h45min & 70 & & 220 & 320 \\
\hline 07-09.2006 & $49 \mathrm{~h}$ & 48 & & 210 & 312 \\
\hline $10-12.2006$ & 47h30min & 45 & & 215 & 315 \\
\hline 2007 & $50 \mathrm{~h}$ & & & & \\
\hline 01-03.2007 & $50 \mathrm{~h}$ & 46 & & 210 & 320 \\
\hline
\end{tabular}

Table 3. Performance characteristics of engine 3AL.25 during the test period.

\begin{tabular}{|c|c|c|c|c|c|}
\hline \multicolumn{2}{|c|}{ Working Time } & \multicolumn{2}{c|}{ Average load } & \multirow{2}{*}{ RPM } & $\begin{array}{c}\text { The temperature in the cylinder } \\
{\left[{ }^{\circ} \mathrm{C}\right]}\end{array}$ \\
\hline Year & Hours & $\%$ & $\mathrm{~kW}$ & 750 & 375 \\
\hline 2006 & 20 & 50 & 170 & & 375 \\
\hline & 40 & & & 750 & 405 \\
\hline & 16 & 50 & 170 & 750 & 375 \\
\hline & 24 & 75 & 250 & & 405 \\
\hline & 67 & & & 750 & 440 \\
\hline & 27 & 50 & 170 & 750 & 375 \\
\hline & 10 & 75 & 250 & 750 & 405 \\
\hline 31.03 .2010 & 30 & 90 & 300 & & 405 \\
\hline
\end{tabular}

crankshafts and rotors of ship generators. Chemical composition of powder was: C- $1.45 \%$; Co$38.9 \%$; Cr-24.13\%; Ni-10.43\%; W-8.75\%; Fe$7.64 \%$; Mo-7.56\%; Si-2.59\%. Valves with faces covered with layers made of these two alloys have been installed in the engine on the ship "Dar Młodzieży". AL 20/24 engine has the following parameters: in-line engine, 8-cyliners; cylinder diameter $200 \mathrm{~mm}$; piston stroke $240 \mathrm{~mm}$; swept capacity $7540 \mathrm{~cm}^{3}$; nominal rotational speed $720 / 750 \mathrm{rev} / \mathrm{min}$ or $900 / 1000 \mathrm{rev} / \mathrm{min} ; 136 \mathrm{~kW} /$ Cyl. The L22 engine with remanufactured exhaust valve trim has run for 210 hours and 30 minutes. The average load was about $60 \%$, the average rpm $212 \mathrm{~min}^{-1}$ (Table 2).
The 3AL.25 engine with regenerated exhaust valve clamps has been running for 210 hours, average load was about $50 \%$, rpm $750 \mathrm{~min}^{-1}$. Rated power $455 \mathrm{hp}(335 \mathrm{~kW})$ (Table 3). The engine AL 20/24 on the ship "Dar Młodzieży" with regenerated outlet valve clamps has worked 3000 hours (Table 4 ).

After 2000 hours of service valve L12 was still intact without of any traces of serious failure but valve $\mathrm{N}$ was completely destroyed. Figure 2 presented the state of the valve $\mathrm{N}$ after operation. On the right side of the figure there is visible broken (A) part of the valve and the layer of surfacing (B) has practically disappeared. The damage also applies to the valve plug $(\mathrm{C})$. The L12 valve 
Table 4. Characteristics of engine parameters AL 20/24 during the test period.

\begin{tabular}{|c|c|c|c|c|}
\hline \multicolumn{2}{|l|}{ Working Time } & \multirow{2}{*}{$\begin{array}{c}\text { Average load } \\
\text { Setting on the fuel bar }\end{array}$} & \multirow{2}{*}{ RPM } & \multirow{2}{*}{$\begin{array}{l}\text { Average exhaust temperature } \\
\qquad\left[{ }^{\circ} \mathrm{C}\right]\end{array}$} \\
\hline Year & Hours & & & \\
\hline $\begin{array}{l}\text { From } 27.09 .2007 \text { to } 10.12 .2007 \\
\text { Engine Log Book No } 102\end{array}$ & \multicolumn{4}{|c|}{ October 27th - installation of remanufactured valves } \\
\hline $\begin{array}{l}\text { From } 11.12 .2007 \text { to } 23.02 .2008 \\
\text { Engine Log Book No } 103\end{array}$ & 6.3 & variable & 750 & variable \\
\hline $\begin{array}{c}\text { From 24.02.2008 to } 08.05 .2008 \\
\text { Engine Log Book No } 104\end{array}$ & 388.3 & 5.1 & 750 & 363 \\
\hline $\begin{array}{c}\text { From } 09.05 .2008 \text { to } 22.07 .2008 \\
\text { Engine Log Book No } 105\end{array}$ & 716.2 & 5.5 & 750 & 369 \\
\hline $\begin{array}{c}\text { From } 23.07 .2008 \text { to } 08.10 .2008 \\
\text { Engine Log Book No } 106\end{array}$ & 724.5 & 5.3 & 750 & 372 \\
\hline $\begin{array}{l}\text { From 06.10.2008 to } 19.12 .2008 \\
\text { Engine Log Book No } 107\end{array}$ & 11 & variable & 750 & variable \\
\hline $\begin{array}{c}\text { From } 20.12 .2008 \text { to } 04.03 .2009 \\
\text { Engine Log Book No } 108\end{array}$ & 18.9 & 5.1 & 750 & 318 \\
\hline $\begin{array}{c}\text { From } 05.03 .2009 \text { to } 18.05 .2009 \\
\text { Engine Log Book No } 109\end{array}$ & 170.7 & 5.1 & 750 & 338 \\
\hline $\begin{array}{c}\text { From } 19.05 .2009 \text { to } 01.08 .2009 \\
\text { Engine Log Book No } 110\end{array}$ & 321.8 & 5.2 & 750 & 355 \\
\hline $\begin{array}{c}\text { From 02.08.2009 to } 15.10 .2009 \\
\text { Engine Log Book No } 111\end{array}$ & 359.6 & 5.5 & 750 & 375 \\
\hline $\begin{array}{c}\text { From } 16.10 .2009 \text { to } 29.12 .2009 \\
\text { Engine Log Book No } 112\end{array}$ & 5 & variable & 750 & variable \\
\hline $\begin{array}{c}\text { From } 30.12 .2009 \text { to } 14.03 .2010 \\
\text { Engine Log Book No } 113\end{array}$ & \multicolumn{4}{|c|}{ Tuesday. 12.01.2010 - the examination was completed } \\
\hline
\end{tabular}

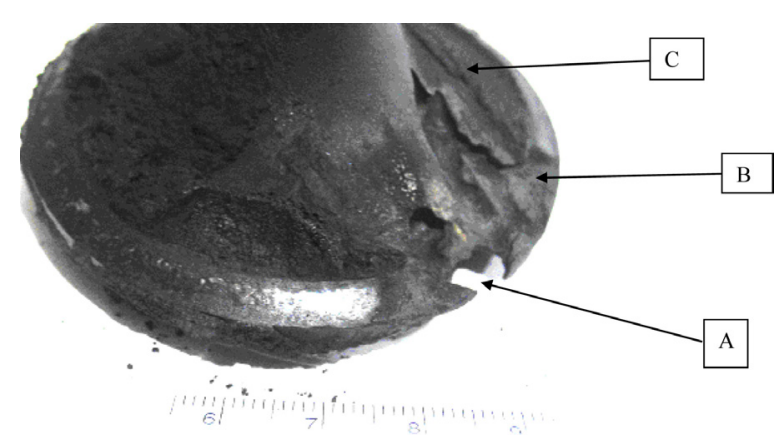

Fig. 2. N valve after 2000 hours of operation

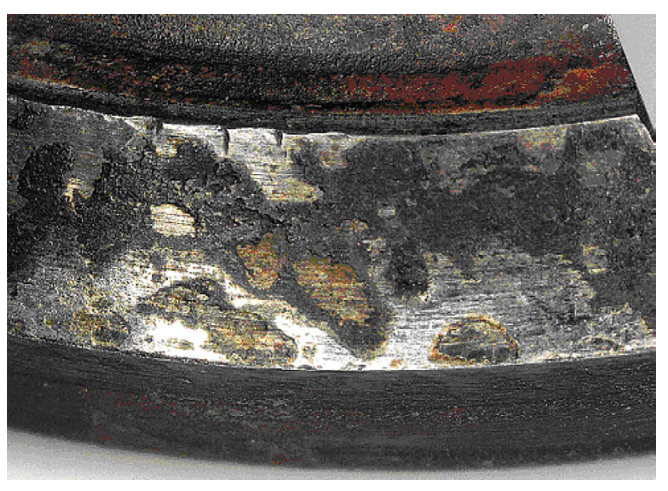

Fig. 3. L12 valve after 3000 hours of operation. Magnification 10x after 3000 hours of operation did not show any significant signs of wear or damage (Fig. 3).

The L12 valve shows little signs of degradation after a longer operating time. Some regions of the scale are visible however some of the face is still shiny and smooth. Detailed investigations were carried out on the face surfaces of both valves and microstructures on the cross-section of the analyzed valves. In addition, hardness measurements were carried out to assess the degree of material degradation. During the operation and heat interaction, diffusion processes occur in the surfacing material leading to changes in the structure. Mainly the formation of oxides on the surface causes the decomposition of carbides and a decrease in the hardness of the material. Microhardness tests are very sensitive to microstructure changes.

\section{FAILURE ANALYSIS}

A scanning electron microscope (SEM JSM7800F with EDS Octane Elite) was used for metallographic examinations which allowed the analysis of the valve face surfaces and microstructures on the cross-sections perpendicular to the face surface. Figure 4 shows the surface 

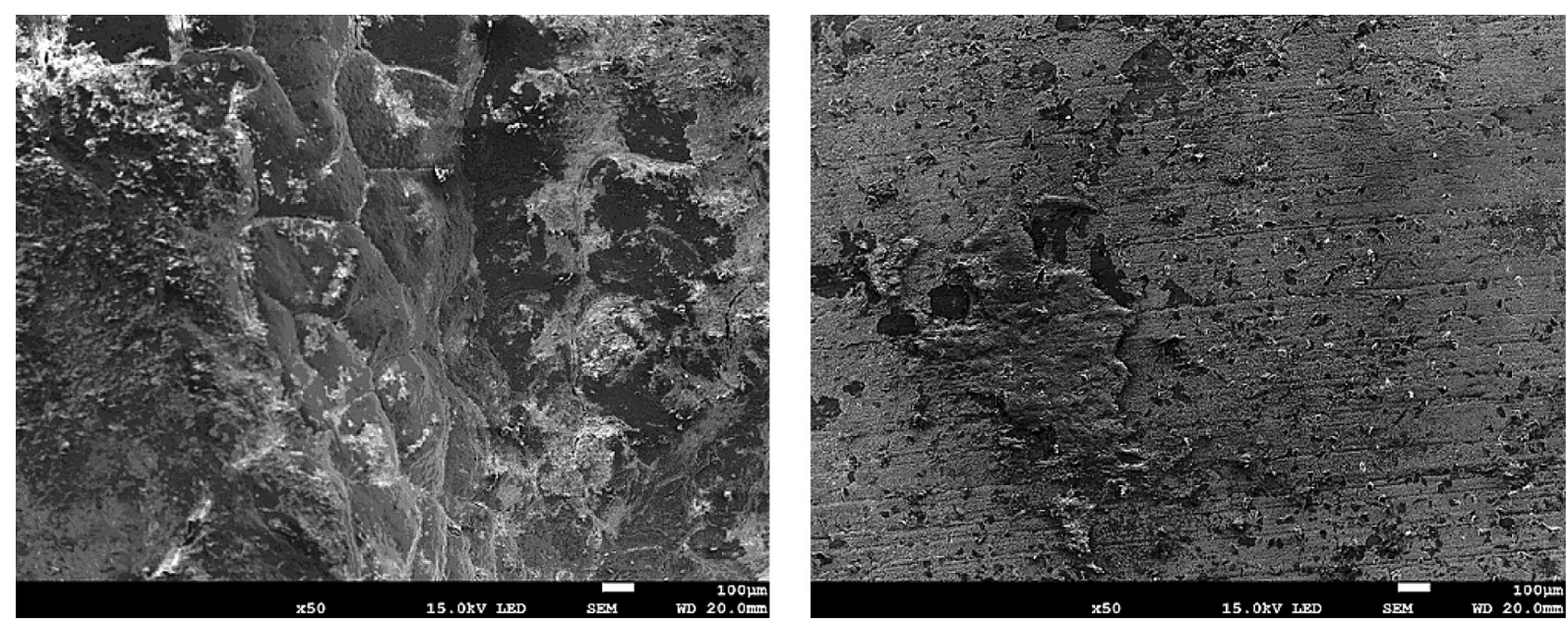

Fig. 4. $\mathrm{N}$ valve destroyed during operation - face surface (a), face surface in a different area (b)
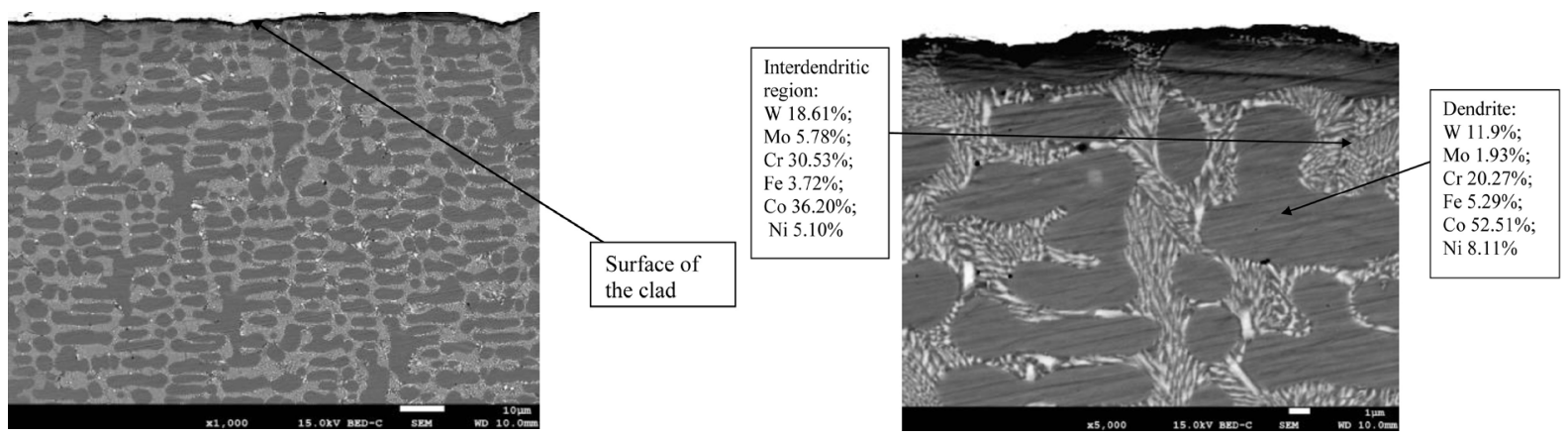

Fig. 5. $\mathrm{N}$ valve destroyed during operation - microstructure on the cross-section, close to the face surface; it is visible dendritic structure characteristic for free solidification of melted metal during surfacing (a); microstructure on the cross-section, near the top surface; EDS results for dendritic and interdendritic region (point analysis) (b)

condition of the N valve after service. Significant differences of the appearance of the valve face surface were observed. It also indicates different properties of the material in different area of the face which is not acceptable.

Observed destruction of the face can be caused by various factors. It may be the result of incorrect selection of padding materials, improper parameters of the padding process, but also mechanical causes of damage, i.e. overloading or improper valve grinding should be taken into account. In this work only chemical composition of the clad and changes in mikrostrusture were analized.

The valve was cut into samples, included and a specimen prepared, which was observed on a scanning electron microscope (SEM). On Figure 5 is presented mikrostructue of destroyed valve N. Mikrostructure is typical for cladding technology $[3,4,10,26]$; visible dendritic structure (dark) and interdendritic regions (light under low magnification). Dendritic region are a solution of alloying additives in cobalt, mainly nickel, iron, chromium, tungsten and molybdenum. The interdendritic region consist of mixture of carbides end eutectics (Fig. 5a). During previous tests of welds made of the same powder as designated L12, occurrence was found was found by XRD analysis presence of carbides were identified as mainly $\mathrm{M}_{12} \mathrm{C}\left(\mathrm{Co}_{6} \mathrm{~W}_{6} \mathrm{C}\right), \mathrm{M}_{7} \mathrm{C}_{3}$ and $\mathrm{M}_{23} \mathrm{C}_{6}$ $\left(\mathrm{Cr}_{23} \mathrm{C}_{6}\right)$. EDS analysis shows a significant presence of tungsten, chromium and molybdenum

The L12 valve, undamaged after 3000 hours of operation, was tested the same way. Throughout the operation the valve functioned without any problems. It was dismounted and inspected. Despite the proper operation of the engine throughout the entire test period, the contact 


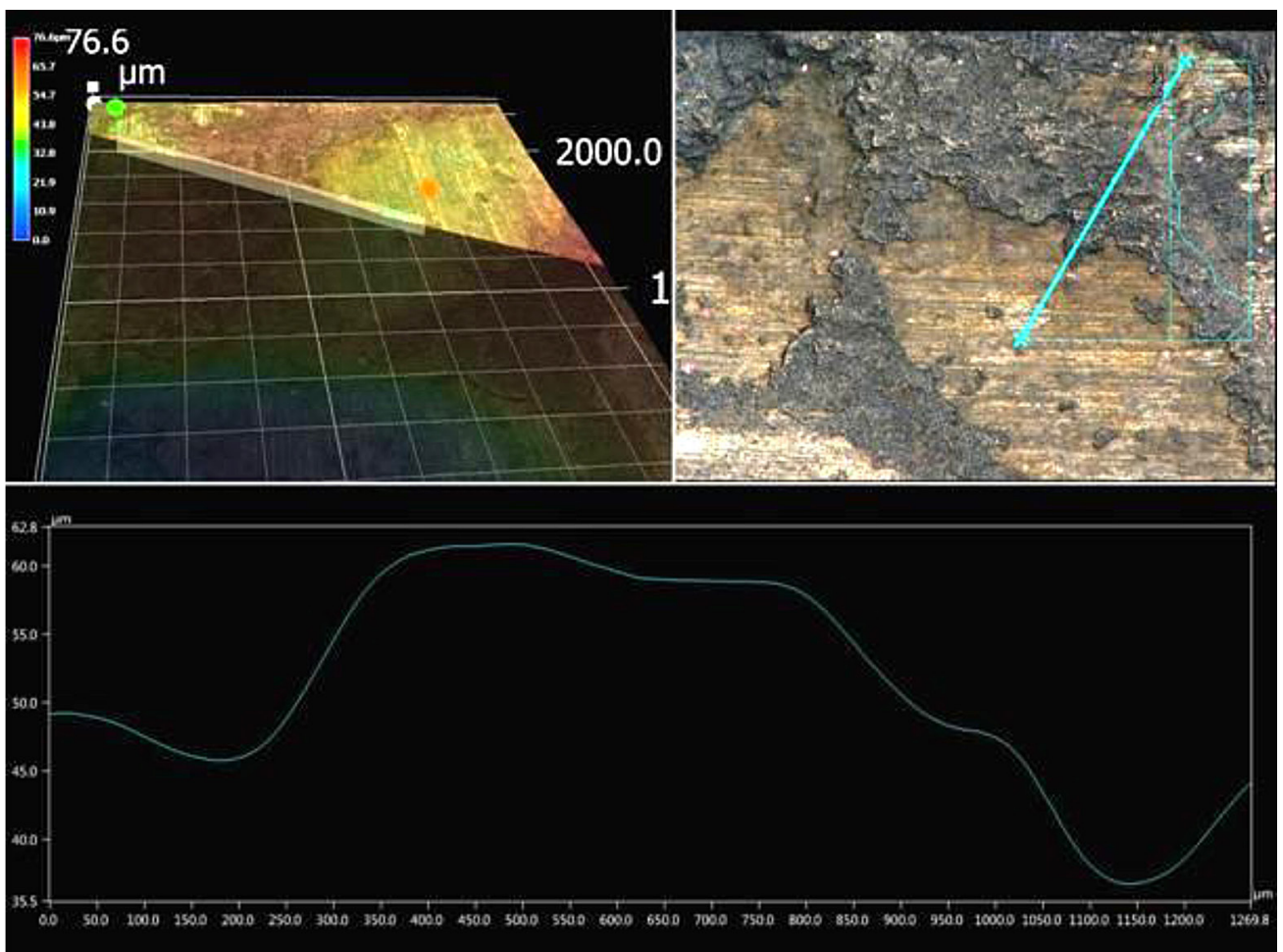

Fig. 6. Surface profile of L12 valve face after operation -visible regions of existing scale. Analyse made by laser profiler KEYENCE

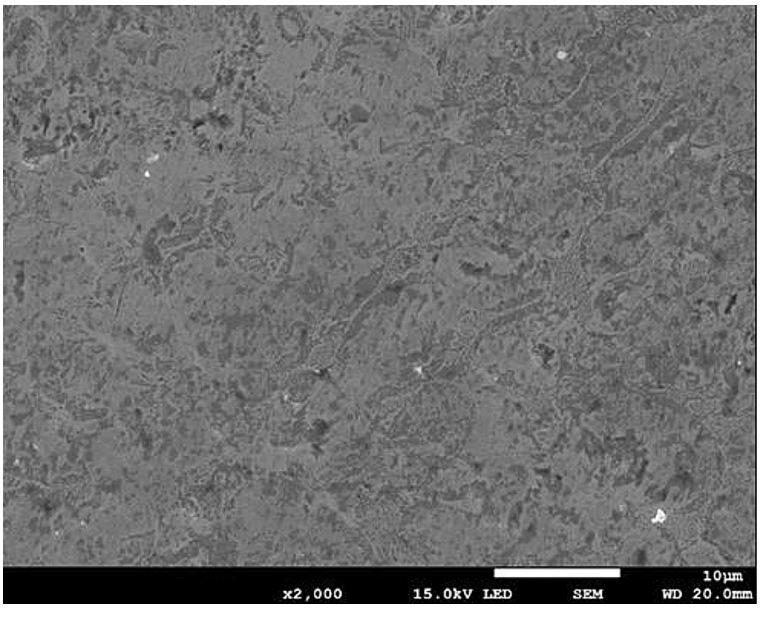

Fig. 7. L12 valve face after operation - plastic deformation

surface of the outlet valve face has been slightly degraded. Keyence equipment was used for surface analysis. This eqipment is a microscope coupled with a profilograph and allows measure the surface profile of targets in $\mathrm{X}$ and $\mathrm{Z}$ directions. The height, width or gap on a surface profile can be measured. Observation of the face surface showed the presence of crumbling scale and areas of the exposed metal surface. In
Figure 6 a multilayer scale with a tendency to crack and delaminate is visible. However, the largest layer thickness did not exceed $60 \mu \mathrm{m}$. SEM analysis of the valve face marked L12 showed the slight plastic deformation of the surface was observed, which can be interpreted as the effects of plastic deformation during work, this is illustrated in Figure 7.

SEM observation of the cladding layer cross-section does not show any significant changes in relation to the typical microstructure of the clad layer. However, the presence of the scale on the face surface indicates changes in chemical composition resulting from diffusion processes. The EDS analysis results for the padding area just below the scale was as follows: $\mathrm{Si}-2.49 \%$; $\mathrm{Cr}-23.12 \%$; $\mathrm{Fe}-31.83 \%$; Co-35.30\%; Ni-0.60\%; W-5.79\%; Mo-0.86\%. It may cause changes in material hardness because the scale is mainly composed of chromium oxide, which has protective properties. This is also the reason for using alloys with such high chromium content. Chromium is mainly contained in carbide secretions and they are also the main source of diffusion to the surface. Degradation of carbides decreases the hardness of the material $[10,24,25]$. 

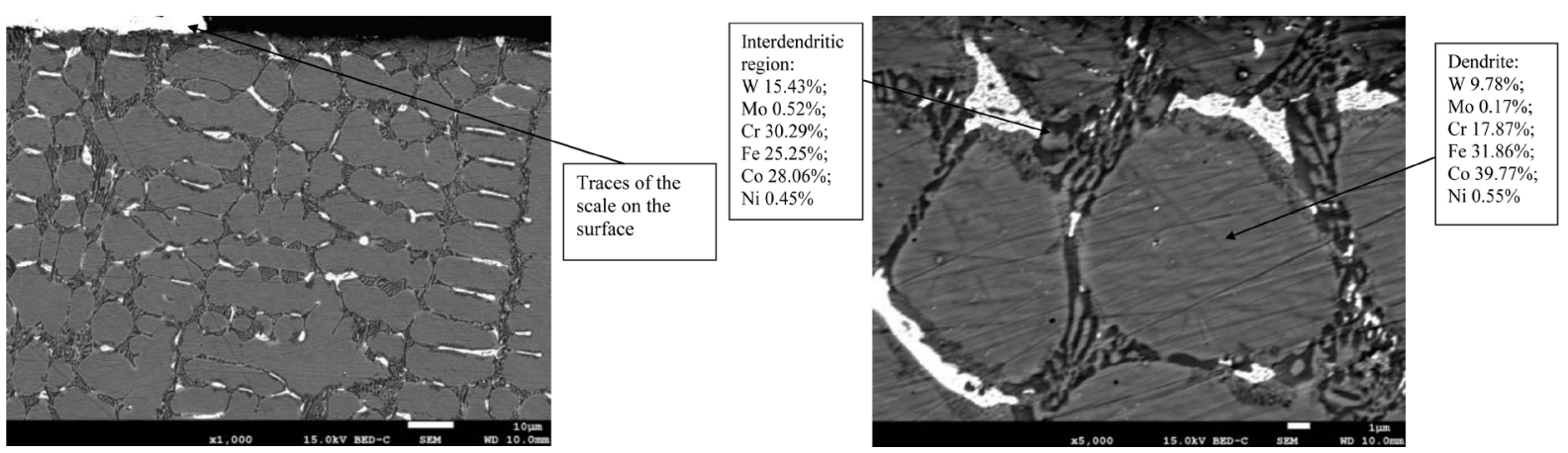

Fig. 8. (a) L12 after operation - microstructure on the cross-section, near the top surface. No visible changes in dendritic microstructure under the scale (b) L12 after operation - microstructure on the crosssection, near the top surface. EDS results for dendritic and interdendritic region (point analysis)

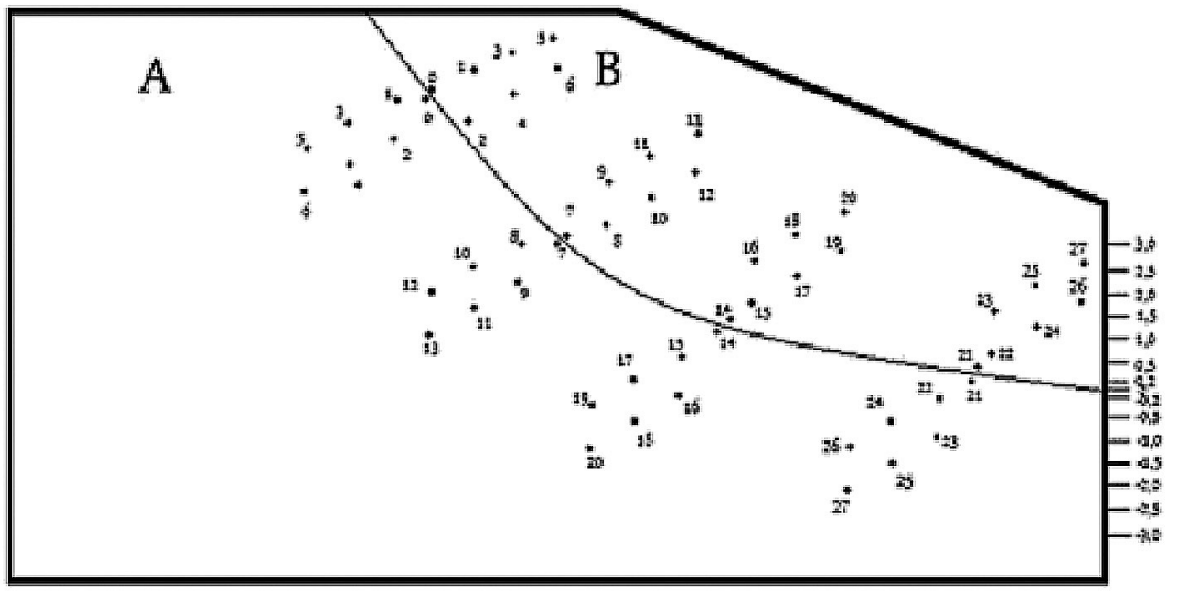

Fig. 9. Positions of the hardness measurement points on the cross-section of the cladded layer and the substrate; $\mathrm{A}$ - steel base, $\mathrm{B}$ - cladding layer

\section{HARDNESS MEASUREMENT}

After the operation period, the hardness profiles across the thickness of clad and substrate were measured on a FM800 hardness meter at 49N load using the Vickers method. Any hardness data reported here were statistic averages of at least four measurements. Due to the technology of applying the layer, the hardness measurement was carried out according to developed scheme shown in Figure 9.

Due to the heterogeneous structure of the material four measurement series were made, the mean hardness value and the confidence interval were determined. The non-uniform hardness across the coating was a result of multilayer producing process and structure of this layer. The heat affected zone (HAZ) was observed in the steel under the clad layer. From the morphological point of view, the measured differences in hardness were affected by the dendrite structure and can also be attributed to the morphology of the carbides $[6,12,16]$. This phenomenon is related to the multiple heating and cooling during the multilayer cladding process. The heat treatment in high temperature and exhaust gases atmosphere may led to the changes in the hardness especially in the upper part of the clad. The results are shown in Figures 10-12. In each of the examined cases, the hardness of the surfacing layer was significantly higher than the hardness of the substrate. In the case of L12 sample hardness was found in the range 473 to $581 \mathrm{HV} 5.0$ at distance $3 \mathrm{~mm}$ from the steel-clad interface (close to clad top surface) and remained at a similar value to a distance of $1 \mathrm{~mm}$ from the interface. In the fusion line hardness was rapidly falling to value 231-251 HV5.0. The obtained results indicate an uniform hardness of the entire weld. In the case of $\mathrm{N}$ sample hardness was 


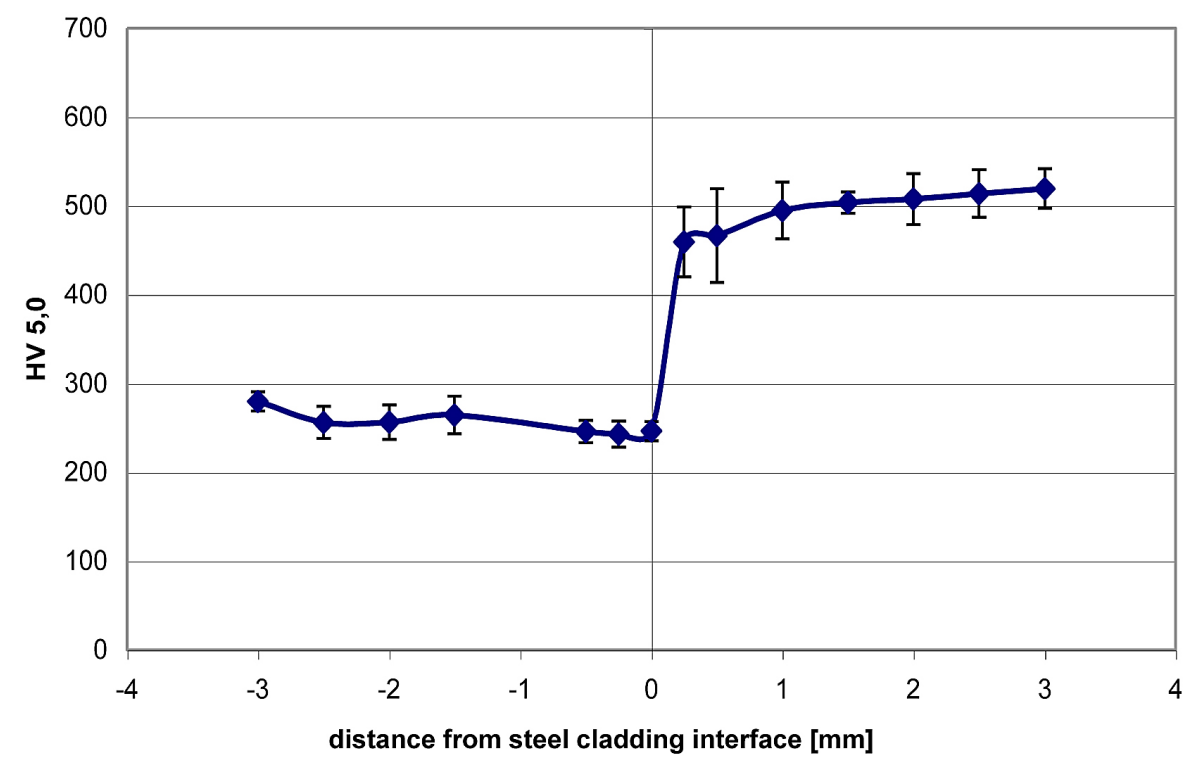

Fig. 10. Statistical analysis of the hardness measurements for the L12 valve after 3000 hours of operation

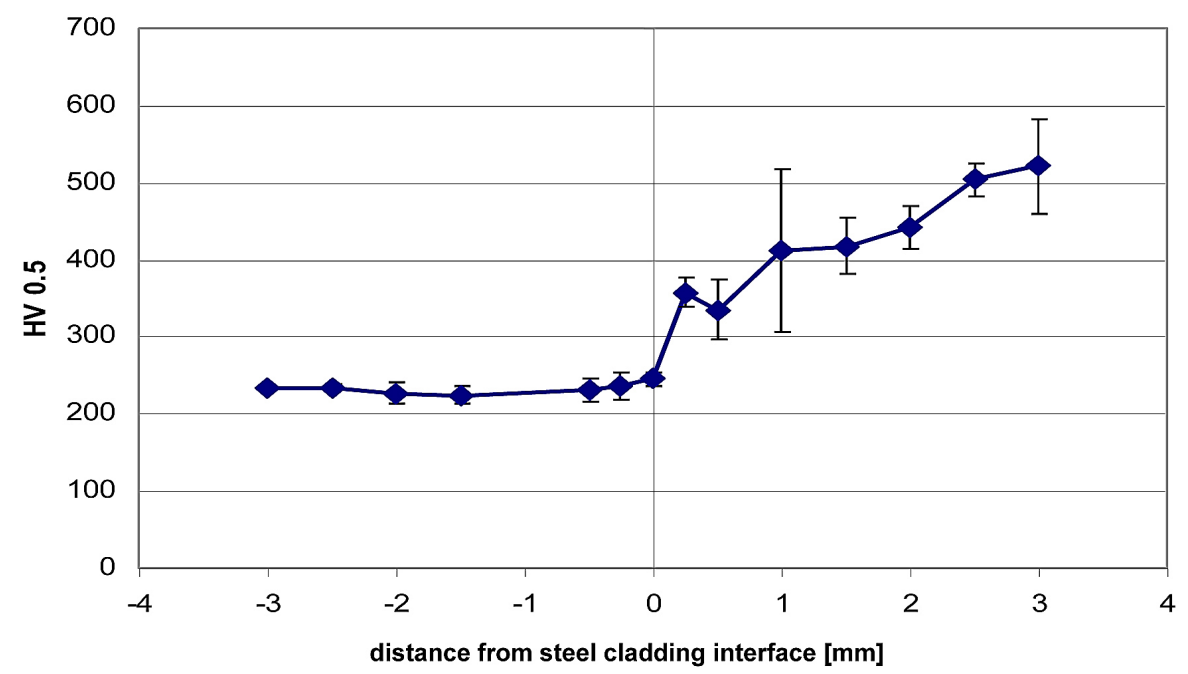

Fig. 11. Statistical analysis of the hardness measurements for $\mathrm{N}$ valve after 2000 hours of operation

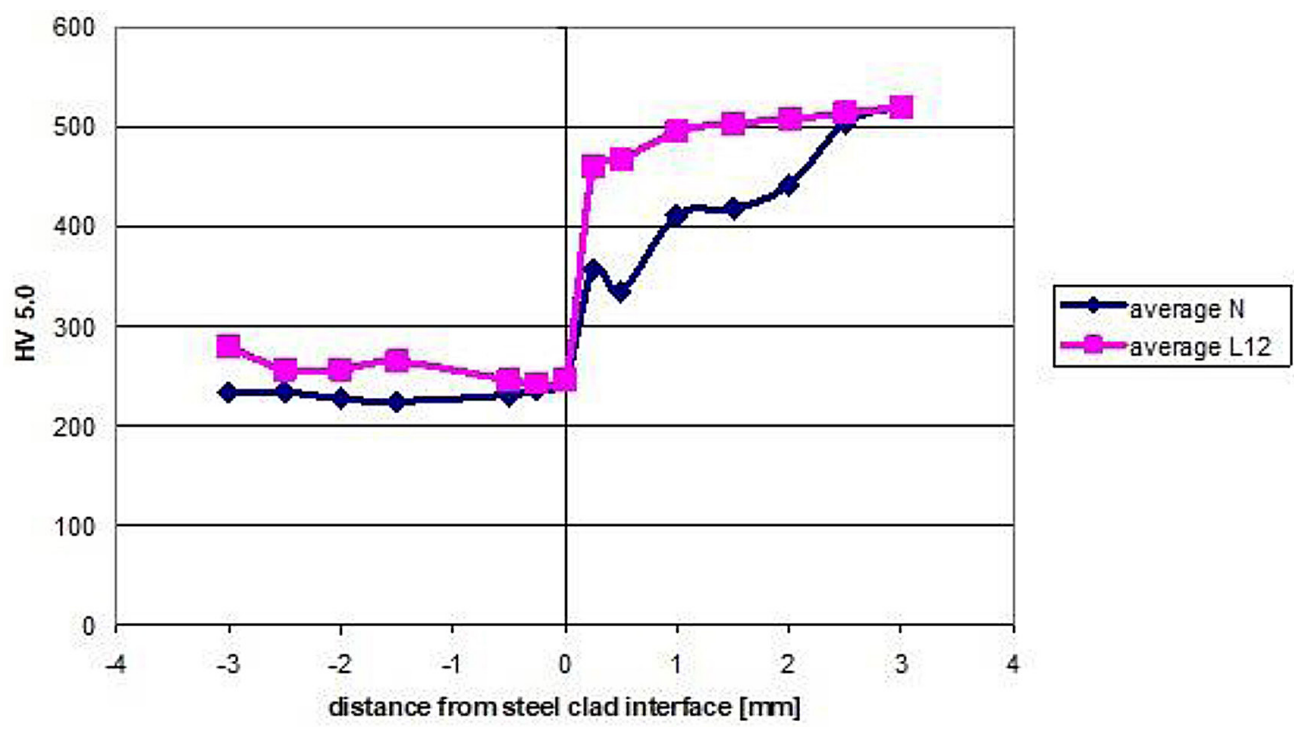

Fig. 12. Comparison of average values of hardness of the $\mathrm{N}$ and L12 faces claddings 
found in the range 480 to 581 HV5.0 at distance $3 \mathrm{~mm}$ from the steel-clad interface (close to clad top surface) - similar to L12, but in the deep of the clad hardness decreases up to 195-447 HV5.0. In means large changes in hardness on the cross-section. In both cases no significant decrease in hardness was observed close to the top surface, which indicates that despite the formation of the oxide layer, no degradation of the material will occur.

\section{CONCLUSIONS}

1. The cladding process provided both clad layers on the valve faces with a correct structure, typical for cladding process. It means dendritic structure.Dendritic region are a solution of alloying additives in cobalt, mainly nickel, iron, chromium, tungsten and molybdenum. Interdendritic region consist of mixture of eutectics end carbides identified as mainly $\mathrm{M}_{12} \mathrm{C}$ $\left(\mathrm{Co}_{6} \mathrm{~W}_{6} \mathrm{C}\right), \mathrm{M}_{7} \mathrm{C}_{3}$ and $\mathrm{M}_{23} \mathrm{C}_{6}\left(\mathrm{Cr}_{23} \mathrm{C}_{6}\right)$.

2. The analyzes confirmed the usefulness of the stellite 12 type alloy (in this case clad layer marked L12) for operation in a marine engine. Experimental composition marked $\mathrm{N}$ was prematurely damaged, however microstructure analysis showed no abnormalities. The obtained images of L12 and $\mathrm{N}$ microstructures showed significant similarities.

3. Hardness measurements showed stable hardness of the L12 surfacing weld, higher than the hardness of the substrate. While a constant decrease in the hardness of the $\mathrm{N}$-weld surfacing across the thickness is observed which could affect its durability.

4. It is also important to consider the possible mechanical factor. This would imply irregular wear of the seat in the undamaged area of the $\mathrm{N}$ valve. Improper valve fitting may led to premature valve failure. Incorrect grinding-in could cause the valve to leak and, as a consequence, to blow hot exhaust gases. This caused a local increase in temperature and intense destruction.

\section{REFERENCES}

1. Ahmed K., Helmi A., Vince T., Saeid O. Characterization of fretting wear of cobalt-based superalloys at high temperature for aero-engine combustor components. Wear, 330-331, 2015, 327-337.

2. Almazrouee A., Al-Faheed S., Shalaby H.M. Crack- ing of a cobalt-based hardfacing of a gate valve disk in a desalination power plant. Journal of materials engineering and performance 22.5, 2013, 1436-1442.

3. Ana Sofia C.M. D’Oliveira, P. Se'rgio C.P. da Silva, Rui M.C. Vilar. Microstructural features of consecutive layers of Stellite 6 deposited by laser cladding. J. Surf.Coat.Technol., 153, 2002, 203-209.

4. Aoh J.N., Jeng Y.R., Chu E.L., Wu L.T. On the wear behavior of surface clad layers under high temperature, Wear 225-229, 1999, 1114-1122.

5. Apay, Serkan, Behcet Gulenc Wear properties of AISI 1015 steel coated with Stellite 6 by microlaser welding, Materials \& Design, 2014, 55.

6. Berthod P., Michon S., Di Martino J., Mathieu S., No“el S., Podor R., Rapin C. Thermodynamic calculations for studying high temperature oxidation of superalloys, Computer Coupling of Phase Diagrams and Thermochemistry 27, 2003, 279-288.

7. Cui, Chengyun, et al. Characteristics of cobaltbased alloy coating on tool steel prepared by powder feeding laser cladding. Optics \& Laser Technology 39.8, 2007, $1544-1550$.

8. Frenk A., Kurz W. High speed laser cladding: solidification conditions and microstructure of a cobaltbased alloy. Materials Science and Engineering, A, 1993 - Elsevier.

9. Gholipour, A., Shamanian, M., Ashrafizadeh, F. Microstructure and wear behavior of satellite 6 cladding on 17-4 PH stainless steel. J. Alloy Compd. 509, 2011, 4905-4909.

10. Hao, C., Chun-xu, P. Microstructure and fractural morphology of cobalt-based alloy laser cladding. J. Wuhan Univ. Technol.-Mat. Sci. Edit. 18, 2003, 30-32.

11. Hejwowski T. Investigation of corrosion resistance of $\mathrm{Fe}, \mathrm{Ni}$ and Co-based hardfacing; Vacuum, vol.80, issue 11-12, 2006, 1386-1390.

12. Hou P. Y., Stringert J. Oxidation of Metals, Vol 33, 1990, Nos. 5/6.

13. Ion, J. C. Laser processing of engineering materials. Elsevier, Oxford 2005.

14. Jeng M. C., Yan L. Y., Doong J. L. Wear behaviour of cobalt-based alloys in laser surface cladding. J. Surf.Coat.Technol. 48, 1991, 225-231.

15. Jiang W.H., Yao X. D., Guan H. R., Hu Z.Q. Relationship between degeneration of $\mathrm{M} 7 \mathrm{C} 3$ and precipitation of M23C6 in a cobalt base superalloy, Materials Science and Technology, Vol. 15, Issue. 5, London 1999, pg 596, 3.

16. Li B., Gleeson B. Oxidation of Metals Volume: 65, Issue: 1-2, 2006, pp. 101 - 122.

17. Lin W.C., Chen C., Characteristics of thin surface layers of cobalt-based alloys deposited by laser cladding. J. Surf.Coat.Technol. 200 , 2006, 4557-4563.

18. Liu R., Yao M. X., Patnaik P. C., Wu X. J. An Improved Wear-resistant PTA Hardfacing: VWC/Stel- 
lite 21, Journal of Composite Materials, Vol 40, Issue 24, 2006.

19. Lucjan W. Failure and thermo-mechanical stress analysis of the exhaust valve of diesel engine. Engineering Failure Analysis 66, 2016.

20. Maher A.R. Sadiq Al-Baghdadi, Sahib Shihab Ahmed, Nabeel Abdulhadi Ghayadh, Mechanical and thermal stresses analysis in diesel engine exhaust valve with and without thermal coating layer on valve face, International journal of energy and environment, Volume 7, Issue 3, 2016.

21. Munro C.D. Analysis of a failed Detroit Diesel series 149 generator. Engineering Failure Analysis 35, 2013.

22. Scharf, Thomas W. et al. Elevated temperature tribology of cobalt and tantalum-based alloys. Wear 330, 2015, $199-208$.

23. Schlager D., Theiler C., Kohn H. Protection against high temperature corrosion with laser welded claddings, applied and tested on exhaust valve discs of large diesel engines burning heavy fuel oil, Materials and Corrosion 53, 2002, 103-110.
24. Shin J.C., Doh J.M., Yoon J.K., Lee D.Y., Kim J.S. Effect of molybdenum on the microstructure and wear resistance of cobalt-base Stellite hardfacing alloys. Surface and Coatings Technology 166, 2003,117-126.

25. Smoleńska H. Effect of temperature and gaseous medium on the structure and microhardness of the cobalt base clad layers, Chemicke Listy. - Vol. 104, issue 15, 2010, 371-374.

26. Szala M., Hejwowski T., Lenart I. Cavitation erosion resistance of Ni-Co coatings; Advances in Science and Technology Rersearch Journal 8(21), 2014, 36-42.

27. Xue, Lijue, et al. Integrated rapid 3D mapping and laser additive repair of gas turbine engine components. 2013 ICALEO Conference Proceedings, 2013.

28. Yinping Ding, Rong Liu, Jianhua Yao, Qunli Zhang, Liang Wang, Stellite alloy mixture hardfacing via laser cladding for control valve seat sealing surfaces, Surface and Coatings Technology 329, 2017. 